Earlier, before the Dingell congressional hearings under which David was investigated for his support of a colleague accused of scientific fraud, I had in fact tried to defuse the situation, first by holding a small meeting on scientific integrity at our Banbury Center to try to review what was going on. Although invited, David declined to come, but his close associates did. Second, I went to the offices of Congressman Norman Lent, Long Island's Republican counterpart to John Dingell, to tell him that the controversy involved not fraud but possible mistakes of scientific judgment, and as such it should not merit the attention of a congressional committee.

I have only the highest respect for Baltimore as a scientist and leader of science, but his intransigence at the time made many of us worry that the affair was harming not only himself but US science as well. I in no way feel apologetic for not supporting behaviour that I feel is antithetical to the scientific tradition in which I was raised. The Harvard professors who saw the need to publicly question David's behaviour only reluctantly joined the fray. In reporting their and my behaviour as "horrid", Bazell does us a great injustice. Under no circumstances could John Edsall or Paul Doty, say, be accused of jealousy of a peer's meteoric career. I and the Harvard professors were deeply bothered by what seemed to us actions not appropriate for an individual of such talents. I totally concurred in my former colleagues' forthright wish for justice to prevail.

James D. Watson

Cold Spring Harbor Laboratory, PO Box 100, Cold Spring Harbor, New York 11724, USA

\section{How inbreeding affects productivity in Europe}

Sir - Navarro and Rivero in Correspondence ${ }^{1}$ for the first time quantified favouritism ("inbreeding") in Spanish universities, showing that it is at least 10 times higher than in France, the United States and the United Kingdom. I have now quantified this phenomenon in 51 universities from 14 European countries.

I examined the relationship between the percentage of papers published by each country and its level of inbreeding. I gathered information from 51 ecology or zoology departments via a brief questionnaire requesting information on the number and rank of teaching positions, as well as the number of these staff trained at the same university.
I obtained responses from at least two universities in each country. I estimated "inbreeding" as the percentage of staff in these positions trained at the university. I found significantly more variance in inbreeding among than within countries $(F=12.38$, d.f. $=13,37, P<0.0000001$; one-way analysis of variance), showing that countries are consistent in their degree of favouritism.

Spain registered the second highest level of inbreeding, averaging $88 \%$, surpassed only by Portugal (91\%). Figures for the remainder are (in \%): Italy (78), Austria (73), France (65), Norway (56), Belgium (52), Finland (48), Netherlands (40), Denmark (39), Sweden (32), Switzerland (23), United Kingdom (5.2) and Germany (1).

To explore the relationship between level of inbreeding and scientific productivity, I used May's enlightening report ${ }^{2}$, in which he assesses the quality of the contribution of various countries to world scientific knowledge. May provides information about the share of papers and citations in science, medicine and engineering provided by 15 countries, not including Portugal, Spain, Austria, Norway and Belgium. If, conservatively, I assign these countries a value of 0.5 , a significantly negative correlation appears between the percentage of papers published by each country and its level of inbreeding $\left(R_{\mathrm{s}}=-0.60, P=0.02, n=14\right)$. That is, overall scientific productivity correlates negatively with the percentage of inbreeding.

In the 1980s the Spanish government attempted to end inbreeding in its universities by the University Reform Law (LRU). The Real Decreto 1888/1984 of 26 September, which regulates the employment system in Spanish universities, clearly states: "The research activities of the candidates shall be evaluated as the priority merit" (Art. 8.2.a). This reform has, however, failed to change the system ${ }^{3}$; indeed, the problem has become even more serious, as pointed out in two Nature editorials ${ }^{4,5}$.

The inbreeding system is extremely stable. The solution needs vigorous measures: first, every position should be advertised internationally; second, there should be no local members on appointment committees; and third, lecturers or full professors with low scientific productivity should not serve on committees that appoint professorships. As things stand, Spanish universities are autonomous and they do not want the system to change because, in general, university politicians (people who manage universities) are not good researchers and do not consider that scientific productivity is paramount.

When will the Spanish government decide to implement the necessary drastic reforms?

Manuel Soler

Department of Animal and Ecological Biology,

Faculty of Sciences, University of Granada, 18001, Granada, Spain

1. Navarro, A. \& Rivero, A. Nature 410, 14 (2001).

2. May, R. M. Science 275, 793-796 (1997).

3. Rodilla, V. Nature 376, 290 (1997)

4. Nature 389, 767 (1997).

5. Nature 396, 709 (1998).

\section{Philanthropists are paying their dues}

Sir - I would like to add some points to your excellent News Feature on biomedical philanthropy (Nature 410, 140-143; 2001), which highlighted the fact that high-risk research not funded by the National Institutes of Health (NIH) is increasingly being supported by philanthropists.

First, the NIH system is one of the best biomedical research funding systems in the world. NIH support of research and research training has catalysed much of the explosion of biomedical knowledge over the past few decades.

Second, the NIH and other US agencies have freely allowed investigators to patent technological discoveries made while they were supported by government funds, a policy responsible for the great success of many entrepreneurs. It is thus only fair that some of their good fortune is funnelled back to support basic research.

Third, over the past few years the NIH has been seeking and supporting high-risk research, for example the National Eye Institute's new R03 programme, the National Institute on Drug Abuse's CEBRA programme and the R21 programme of the National Institute of Mental Health and National Institute of Neurological Disorders and Stroke.

Programme officers from each of these institutes have personally contacted me to inform me of these initiatives and to encourage me to apply. My own lab's high-risk work has received funding from both NIH and philanthropic sources.

Finally, and perhaps most important, the NIH system is only as good as the quality of peer review. If biomedical researchers are unhappy with the quality of the review process, we need only look to ourselves to improve it.

Ben A. Barres

Department of Neurobiology, Stanford University School of Medicine, Fairchild D235, 299 Campus

Drive, Stanford, California 94305-5125, USA 